Article

\title{
On Convex F-Contraction in $b$-Metric Spaces
}

\author{
Huaping Huang ${ }^{1, *(\mathbb{D})}$, Zoran D. Mitrović ${ }^{2} \mathbb{D}$, Kastriot Zoto $^{3} \mathbb{D}$ and Stojan Radenović 4 \\ 1 School of Mathematics and Statistics, Chongqing Three Gorges University, Wanzhou 404020, China \\ 2 Faculty of Electrical Engineering, University of Banja Luka, Patre 5, \\ 78000 Banja Luka, Bosnia and Herzegovina; zoran.mitrovic@etf.unibl.org \\ 3 Department of Mathematics and Computer Sciences, Faculty of Natural Sciences, University of Gjirokastra, \\ 6001 Gjirokastra, Albania; zotokastriot@yahoo.com \\ 4 Faculty of Mechanical Engineering, University of Belgrade, Kraljice Marije 16, 11120 Beograd, Serbia; \\ radens@beotel.net \\ * Correspondence: huaping@sanxiau.edu.cn
}

check for

updates

Citation: Huang, H.; Mitrović, Z.D.; Zoto, K.; Radenović, S. On Convex $F$-Contraction in $b$-Metric Spaces. Axioms 2021, 10, 71. https:// doi.org/10.3390/axioms10020071

Academic Editors: Alexander Šostak and Hsien-Chung $\mathrm{Wu}$

Received: 4 March 2021

Accepted: 15 April 2021

Published: 19 April 2021

Publisher's Note: MDPI stays neutral with regard to jurisdictional claims in published maps and institutional affiliations.

Copyright: (C) 2021 by the authors. Licensee MDPI, Basel, Switzerland. This article is an open access article distributed under the terms and conditions of the Creative Commons Attribution (CC BY) license (https:// creativecommons.org/licenses/by/ $4.0 /)$.

\begin{abstract}
In this paper, we introduce a notion of convex F-contraction and establish some fixed point results for such contractions in $b$-metric spaces. Moreover, we give a supportive example to show that our convex $F$-contraction is quite different from the $F$-contraction used in the existing literature since our convex $F$-contraction does not necessarily contain the continuous mapping but the $F$-contraction contains such mapping. In addition, via some facts, we claim that our results indeed generalize and improve some previous results in the literature.
\end{abstract}

Keywords: F-contraction; convex F-contraction; fixed point; $b$-metric space

MSC: $47 \mathrm{H} 10 ; 54 \mathrm{H} 25$

\section{Introduction and Preliminaries}

In [1], Wardowski introduced the following concept of F-contraction and proved a fixed point theorem that generalizes the classical Banach contraction mapping principle.

Definition 1 ([1]). Let $(X, d)$ be a metric space and $T: X \rightarrow X$ be a mapping. Then $T$ is called an F-contraction if there exists a function $F:(0,+\infty) \rightarrow \mathbb{R}$ such that

$\left(F_{1}\right) F$ is strictly increasing on $(0,+\infty)$;

$\left(F_{2}\right)$ for each sequence $\left\{\alpha_{n}\right\}$ of positive numbers,

$$
\lim _{n \rightarrow \infty} \alpha_{n}=0 \text { if and only if } \lim _{n \rightarrow \infty} F\left(\alpha_{n}\right)=-\infty \text {; }
$$

$\left(F_{3}\right)$ there exists $k \in(0,1)$ such that $\lim _{\alpha \rightarrow 0^{+}} \alpha^{k} F(\alpha)=0$;

$\left(F_{4}\right)$ there exists $\tau>0$ such that

$$
\tau+F(d(T x, T y)) \leq F(d(x, y))
$$

for all $x, y \in X$ with $x \neq y$.

Remark 1. Definition 1 is the modification of [1] (Definition 2.1). In fact, (2) from [1] says $d(T x, T y)>0$, that is, $T x \neq T y$. Note that $T x \neq T y$ implies $x \neq y$. Hence, $x \neq y$ in $\left(F_{4}\right)$ is weaker condition than $d(T x, T y)>0$ from (2) of [1]. Moreover, our modification does not disturb the main results of [1]. Clearly, compared with $d(T x, T y)>0$ from [1], our $x \neq y$ is more convenient in applications.

Otherwise, by $(1)$ and $\left(F_{1}\right)$, we have

$$
d(T x, T y)<d(x, y)
$$


for all $x, y \in X$ with $x \neq y$. Accordingly, any F-contraction is a contraction.

Remark 2. It follows immediately from (2) that any F-contraction implies that the mapping $T$ is a continuous mapping.

Wardowski [1] proved that any F-contraction has a unique fixed point.

Theorem 1 ([1]). Let $(X, d)$ be a complete metric space and $T: X \rightarrow X$ be an F-contraction. Then, $T$ has a unique fixed point $x^{*}$ in $X$. For every $x \in X$, the sequence $\left\{T^{n} x\right\}$ converges to $x^{*}$.

Since then, several authors proved fixed point results for F-contractions (see [2-13]). However, $F$-contraction has a great limitation since the mapping must be a continuous mapping (see Remark 2). But the continuity is a strong condition. Hence, it restricts the applications greatly.

On the other hand, the concept of $b$-metric space was introduced by Bakhtin [14] or Czerwik [15] which is a great generalization of usual metric space.

Definition 2. A b-metric space $(X, d, s)(s \geq 1)$ is a space defined on a nonempty set $X$ with a mapping $d: X \times X \rightarrow[0,+\infty)$ satisfying the following conditions:

(1) $d(x, y)=0$ if and only if $x=y$;

(2) $d(x, y)=d(y, x)$ for all $x, y \in X$;

(3) $d(x, y) \leq s[d(x, z)+d(z, y)]$ for all $x, y, z \in X$.

In this case, $d$ is called a b-metric on $X$.

Regarding some other concepts, such as the concepts of $b$-convergent sequence, $b$ Cauchy sequence and $b$-completeness, the reader may refer to [16] and the references therein.

In the sequel, unless there is a special explanation, we always denote by $\mathbb{N}$, the set of positive integers, $\mathbb{R}$, the set of real numbers.

Let $(X, d, s)$ be a $b$-metric space and $T$ be a self-mapping on $X$. The Picard sequence of $T$ is given by $\left\{x_{n}\right\}_{n \in \mathbb{N} \cup\{0\}}=\left\{T^{n} x\right\}_{n \in \mathbb{N} \cup\{0\}}$ for any $x \in X$, where $T^{0} x=x$. In this case, for the convenience, throughout this paper, we always denote $d\left(x_{n+1}, x_{n}\right)$ by $d_{n}$, for all $n \in \mathbb{N} \cup\{0\}$.

In this paper, we introduce the concept of convex $F$-contraction and give some sufficient conditions when the Picard sequence of convex $F$-contraction on $b$-metric space satisfies the Cauchy condition. Our results improve the results of Cosentino and Vetro [17]. Our conclusions are some real generalizations of the results of Popescu and Stan [18]. Moreover, we also expand the main results of Wardowski and Dung [13]. Additionally, we pose two problems at the end of the main text. We aim to continue to work in order to solve the problems in the near future.

\section{Main Results}

In this section, we first define a notion called convex $F$-contraction in $b$-metric spaces. Moreover, we give two examples to illustrate our notion is well-defined. Further, we present a fixed point result for such contraction.

Definition 3. Let $(X, d, s)$ be a b-metric space and $T$ be a self-mapping on $X$. We say that $T$ is a convex F-contraction if there exists a function $F:(0,+\infty) \rightarrow \mathbb{R}$ such that Condition $\left(F_{1}\right)$ holds and

$\left(F_{2}^{\alpha}\right)$ for each sequence $\left\{\alpha_{n}\right\}$ of positive numbers, if $\lim _{n \rightarrow \infty} F\left(\alpha_{n}\right)=-\infty$, then $\lim _{n \rightarrow \infty} \alpha_{n}=0$;

$\left(F_{3}^{s}\right)$ there exists $k \in\left(0, \frac{1}{1+\log _{2} s}\right)$ such that $\lim _{\alpha \rightarrow 0^{+}} \alpha^{k} F(\alpha)=0$;

$\left(F_{4}^{\lambda}\right)$ there exist $\tau>0$ and $\lambda \in[0,1)$ such that

$$
\tau+F\left(d_{n}\right) \leq F\left(\lambda d_{n}+(1-\lambda) d_{n-1}\right),
$$


for all $d_{n}>0$, where $n \in \mathbb{N}$.

Remark 3. Definition 3 improves Definition 1 greatly. Indeed, $\left(F_{2}^{\alpha}\right)$ is weaker than Condition $\left(F_{2}\right)$. If $s=1$, then Condition $\left(F_{3}^{s}\right)$ is Condition $\left(F_{3}\right)$. That is to say, $\left(F_{3}^{s}\right)$ expands Condition $\left(F_{3}\right)$. Moreover, if $\lambda=0$, then Condition $\left(F_{4}^{\lambda}\right)$ is a consequence of Condition $\left(F_{4}\right)$.

Example 1. Let $(X, d, s)$ be a $b$-metric space and $T: X \rightarrow X$ be a mapping. Suppose that $T$ is an $F$-contraction of Kannan type, i.e., there exists $\tau>0$ such that

$$
\tau+F(d(T x, T y)) \leq F\left(\frac{1}{2}[d(x, T x)+d(y, T y)]\right)
$$

for all $x, y \in X$ with $x \neq y$.

Choose $F(\alpha)=\ln \alpha, \alpha \in(0,+\infty)$, then $T$ is a convex F-contraction. Indeed, it is obvious that $F$ satisfies Conditions $\left(F_{1}\right),\left(F_{2}^{\alpha}\right)$ and $\left(F_{3}^{s}\right)$. Moreover, $T$ satisfies Condition $\left(F_{4}^{\lambda}\right)$ based on the fact that there exists $\lambda=\frac{1}{2}$ such that

$$
\tau+F\left(d_{n}\right) \leq F\left(\frac{d_{n}}{2}+\frac{d_{n-1}}{2}\right)
$$

for all $d_{n}>0$, where $n \in \mathbb{N}$. That is, (4) becomes $\left(F_{4}^{\lambda}\right)$.

Otherwise, if $F(\alpha)=\ln \alpha, \alpha \in(0,+\infty)$, then from (4) we have

$$
d(T x, T y) \leq K[d(x, T x)+d(y, T y)],
$$

where $K=\frac{e^{-\tau}}{2}<\frac{1}{2}$, i.e., the contraction of Kannan type (see [19]) holds.

Example 2. Let $T$ be an F-contraction of Reich type (see [20]), i.e., there exist $\tau>0$ and $\alpha, \beta, \gamma \in[0,1], \alpha+\beta+\gamma=1$ such that

$$
\tau+F(d(T x, T y)) \leq F(\alpha d(x, y)+\beta d(x, T x)+\gamma d(y, T y)),
$$

for all $x, y \in X$ with $x \neq y$.

Choose $F(\alpha)=-\frac{1}{\sqrt{\alpha}}, \alpha \in(0,+\infty)$, then $T$ is a convex F-contraction. Indeed, it is clear that $F$ satisfies Conditions $\left(F_{1}\right),\left(F_{2}^{\alpha}\right)$ and $\left(F_{3}^{s}\right)$. Moreover, $T$ satisfies Condition $\left(F_{4}^{\lambda}\right)$ because there exists $\lambda=\beta$ such that (3) holds. That is, T satisfies Condition $\left(F_{4}^{\lambda}\right)$.

Otherwise, if $F(\alpha)=-\frac{1}{\sqrt{\alpha}}, \alpha \in(0,+\infty)$, then (5) implies

$$
d(T x, T y)<\alpha d(x, y)+\beta d(x, T x)+\gamma d(y, T y),
$$

which is the contraction of Reich type.

Lemma 1. Let $(X, d, s)$ be a b-metric space and $T$ be a convex F-contraction on $X$. Then, for every $x \in X$, the sequences $\left\{T^{n} x\right\}_{n \in \mathbb{N} \cup\{0\}}$ is a b-Cauchy sequence.

Proof. Choose $x \in X$ and construct a sequence $\left\{x_{n}\right\}$ by $x_{n}=T^{n} x$ for all $n \in \mathbb{N} \cup\{0\}$. If there exists $n_{0} \in \mathbb{N} \cup\{0\}$ such that $x_{n_{0}+1}=x_{n_{0}}$, then

$$
\left\{x_{n}\right\}=\left\{x, T x, T^{2} x, \ldots, T^{n_{0}-1} x, x_{n_{0}}, x_{n_{0}}, \ldots\right\} .
$$

It is valid that $\left\{T^{n} x\right\}_{n \in \mathbb{N} \cup\{0\}}$ is a $b$-Cauchy sequence. The proof is completed.

Without loss of generality, assume that $x_{n+1} \neq x_{n}$ for all $n \in \mathbb{N} \cup\{0\}$. That is to say, assume that $d_{n}>0$ for all $n \in \mathbb{N} \cup\{0\}$. From Condition $\left(F_{4}^{\lambda}\right)$, we have

$$
F\left(d_{n}\right)<\tau+F\left(d_{n}\right) \leq F\left(\lambda d_{n}+(1-\lambda) d_{n-1}\right) .
$$


Using Condition $\left(F_{1}\right)$, we obtain

$$
d_{n}<\lambda d_{n}+(1-\lambda) d_{n-1},
$$

then $0<d_{n}<d_{n-1}$ for all $n \in \mathbb{N}$. Hence, $\left\{d_{n}\right\}$ is a convergent sequence.

In the following, we show $\lim _{n \rightarrow \infty} d_{n}=0$. To this end, we show

$$
\tau+F\left(d_{n}\right) \leq F\left(d_{n-1}\right),
$$

for all $n \in \mathbb{N}$.

Indeed, if (6) is not true, then

$$
\tau+F\left(d_{n}\right)>F\left(d_{n-1}\right),
$$

for some $n \in \mathbb{N}$. Thus, it establishes that

$$
F\left(d_{n-1}\right)<\tau+F\left(d_{n}\right) \leq F\left(\lambda d_{n}+(1-\lambda) d_{n-1}\right) .
$$

Using Condition $\left(F_{1}\right)$, we get

$$
d_{n-1}<\lambda d_{n}+(1-\lambda) d_{n-1},
$$

which means $d_{n-1}<d_{n}$. This is a contradiction.

It follows immediately from (6) that

$$
F\left(d_{n}\right) \leq F\left(d_{0}\right)-n \tau,
$$

for all $n \in \mathbb{N}$. (7) implies $\lim _{n \rightarrow \infty} F\left(d_{n}\right)=-\infty$. Then by Condition $\left(F_{2}^{\alpha}\right)$, it leads to $\lim _{n \rightarrow \infty} d_{n}=0$.

In view of $\lim _{n \rightarrow \infty} d_{n}=0$, then via Condition $\left(F_{3}^{s}\right)$, there exists $k \in\left(0, \frac{1}{1+\log _{2} s}\right)$ such that

$$
\lim _{n \rightarrow \infty} d_{n}^{k} F\left(d_{n}\right)=0
$$

From (7) we obtain

$$
d_{n}^{k} n \tau \leq d_{n}^{k} F\left(d_{0}\right)-d_{n}^{k} F\left(d_{n}\right) .
$$

Combine (8) and (9), it is easy to see that

$$
\lim _{n \rightarrow \infty} d_{n}^{k} n=0 .
$$

Therefore, there exists $n_{0} \in \mathbb{N}$ such that

$$
d_{n} \leq \frac{1}{n^{\frac{1}{k}}}
$$

for all $n \geq n_{0}$. Finally, using [21] (Lemma 11), we claim that $\left\{x_{n}\right\}$ is a $b$-Cauchy sequence.

Theorem 2. Let $(X, d, s)$ be a b-complete b-metric space and $T$ be a continuous convex F-contraction on $X$. Then, $T$ has a fixed point in $X$.

Proof. For any $x \in X$, by Lemma 1 we deduce that the sequence $\left\{T^{n} x\right\}$ is $b$-convergent. Write $x^{*}=\lim _{n \rightarrow \infty} T^{n} x$. Due to the continuity of the mapping $T$, we conclude that $x^{*}$ is a fixed point of $T$.

Remark 4. The continuous condition of Theorem 2 is necessary because there exists discontinuous convex F-contraction. See Example 3 in the sequel. 


\section{Some Results Related to Convex F-Contractions}

In this section, we obtain some results regarding convex $F$-contractions. We give a supportive example to verify that the mapping $T$ with regard to convex $F$-contraction is not necessarily continuous. This fact shows that our convex $F$-contraction is more meaningful than the F-contraction introduced by Wardowski [1] since any F-contraction must contain the continuous mapping $T$ (see Remark 2).

First of all, we present a fixed point theorem for $F$-contraction of Banach type as follows:

Theorem 3. Let $(X, d, s)$ be a b-complete $b$-metric space and $T$ be a self-mapping on $X$. Suppose that there exists a function $F:(0,+\infty) \rightarrow \mathbb{R}$ satisfying Conditions $\left(F_{1}\right),\left(F_{2}^{\alpha}\right),\left(F_{3}^{s}\right)$ and $\left(F_{4}\right)$. Then, T has a unique fixed point $x^{*}$ in $X$. Moreover, for any $x \in X$, the sequence $\left\{T^{n} x\right\}$-converges to $x^{*}$.

Proof. From Condition $\left(F_{4}\right)$ we obtain Condition $\left(F_{4}^{\lambda}\right)$ if we choose $\lambda=0$. So, $T$ is a convex $F$-contraction. Since $\left(F_{4}\right)$ is satisfied, then by Remark $2, T$ is continuous. Now, from Theorem 2 and Lemma 1 , we conclude that for any $x \in X$, there exists $x^{*} \in X$ such that $T x^{*}=x^{*}$ and $x^{*}=\lim _{n \rightarrow \infty} T^{n} x$.

In the following, we prove that the fixed point of $T$ is unique. Indeed, assume that $T$ has another fixed point $y^{*} \in X$, then by $\left(F_{4}\right)$, ones have

$$
F\left(d\left(x^{*}, y^{*}\right)\right)=F\left(d\left(T x^{*}, T y^{*}\right)\right)<\tau+F\left(d\left(T x^{*}, T y^{*}\right)\right) \leq F\left(d\left(x^{*}, y^{*}\right)\right),
$$

which is a contraction.

Remark 5. Note that, from Theorem 3 we get Theorem 1 because in metric spaces $1+\log _{2} s=1$ holds, where $s=1$. Therefore, Theorem 3 generalizes Theorem 1 . lows:

Secondly, we give a fixed point theorem for the F-contraction of Kannan type as fol-

Theorem 4. Let $(X, d, s)$ be a $b$-complete $b$-metric space with $s \in[1,2)$. Let $T$ be an F-contraction of Kannan type, i.e., $T$ satisfies (4). Suppose that there exists a function $F:(0,+\infty) \rightarrow \mathbb{R}$ satisfying Conditions $\left(F_{1}\right),\left(F_{2}^{\alpha}\right)$ and $\left(F_{3}^{s}\right)$. Then, $T$ has a unique fixed point $x^{*}$ in $X$. Moreover, for any $x \in X$, the sequence $\left\{T^{n} x\right\}$-converges to $x^{*}$.

Proof. From Example 1 we obtain that $T$ is a convex $F$-contraction. So, by Lemma 1 we conclude that there exists $x^{*} \in X$ such that $x^{*}=\lim _{n \rightarrow \infty} x_{n}$, where $x_{n}=T^{n} x$ for any $x \in X$. Next, from Condition (4) and $\left(F_{1}\right)$ we obtain

$$
d(T x, T y)<\frac{1}{2}[d(x, T x)+d(y, T y)]
$$

for all $x, y \in X$ with $x \neq y$.

If $x^{*} \neq T x^{*}$, using (10), we have

$$
\begin{aligned}
d\left(x^{*}, T x^{*}\right) & \leq s\left[d\left(x^{*}, x_{n+1}\right)+d\left(x_{n+1}, T x^{*}\right)\right] \\
& \leq s\left(d\left(x^{*}, x_{n+1}\right)+\frac{1}{2}\left[d\left(x_{n}, x_{n+1}\right)+d\left(x^{*}, T x^{*}\right)\right]\right) .
\end{aligned}
$$

Take the limit as $n \rightarrow \infty$ from the above inequality, it follows that

$$
d\left(x^{*}, T x^{*}\right) \leq \frac{s}{2} d\left(x^{*}, T x^{*}\right)<d\left(x^{*}, T x^{*}\right),
$$

which is a contradiction. Hence, $x^{*}=T x^{*}$. 
Finally, we prove the fixed point of $T$ is unique. As a matter of fact, if $T$ has two distinct fixed points $x^{*}$ and $y^{*}$, i.e., $x^{*} \neq y^{*}$, then by (10), it is easy to see that

$$
d\left(x^{*}, y^{*}\right)=d\left(T x^{*}, T y^{*}\right)<\frac{1}{2}\left[d\left(x^{*}, T x^{*}\right)+d\left(y^{*}, T y^{*}\right)\right]=0 .
$$

which is a contradiction.

Remark 6. Similar to Theorem 4, the mapping $T$ has a unique fixed point if $T$ from Theorem 4 is replaced by the F-contraction of Chatterjea type (see [22]), i.e., there exists $\tau>0$ such that

$$
\tau+F(d(T x, T y)) \leq F\left(\frac{1}{2 s}[d(x, T y)+d(y, T x)]\right)
$$

for all $x, y \in X$ with $x \neq y$.

Example 3. Let $X=\mathbb{R}$ and define a mapping $d: X \times X \rightarrow[0,+\infty)$ by

$$
d(x, y)=|x-y|^{p}
$$

for all $x, y \in X$, where $p \in[1,2)$. Then $(X, d, s)$ is a b-metric space with $s=2^{p-1} \in[1,2)$. Let $T: X \rightarrow X$ be a mapping defined by

$$
T x= \begin{cases}0, & \text { if } x \in(-\infty, 2] \\ \frac{1}{2}, & \text { if } x \in(2,+\infty) .\end{cases}
$$

Let $F(\alpha)=\ln \alpha, \alpha \in(0,+\infty)$, then $F$ satisfies $\left(F_{1}\right),\left(F_{2}^{\alpha}\right)$ and $\left(F_{3}^{s}\right)$. Moreover, there exists $\tau=-\ln (2 K)>0$ such that $T$ is an F-contraction of Kannan type, where $K \in\left[\frac{1}{3^{p}}, \frac{1}{2}\right)$ is a constant. Hence, $T$ satisfies (4). Clearly, $T$ is not continuous but by Theorem 4, it has a unique fixed point $x^{*}=0$ in $X$.

Otherwise, it is easy to see that

$$
d(T x, T y) \leq K[d(x, T x)+d(y, T y)]
$$

for all $x, y \in X$. Therefore, $T$ is a contraction for Kannan type. However, $T$ is not a contraction for Banach type. Actually, there is not a constant $k \in(0,1)$ such that

$$
d(T x, T y) \leq k d(x, y)
$$

for all $x, y \in X$.

Remark 7. By Example 3, we claim that Theorem 4 has a superiority since the mapping $T$ does not necessarily be continuous. Hence, our convex F-contraction can derive more applications than the counterpart of all the results regarding F-contraction. This is because any F-contraction must contain a continuous mapping (see Remark 2).

Finally, we give a result on $F$-contraction of Hardy-Rogers type in $b$-metric spaces. Our result improves the results of $[17,18]$ in $b$-metric spaces.

Theorem 5. Let $T$ be a self-mapping on a b-complete b-metric space $(X, d, s)$. Suppose that there exists a function $F:(0,+\infty) \rightarrow \mathbb{R}$ satisfying Conditions $\left(F_{1}\right),\left(F_{2}^{\alpha}\right)$ and $\left(F_{3}^{s}\right)$. If there exists $\tau>0$ such that

$$
\begin{aligned}
\tau+F(d(T x, T y)) \leq & F(a d(x, y)+b[d(x, T x)+d(y, T y)] \\
& +c[d(x, T y)+d(y, T x)]),
\end{aligned}
$$


for all $x, y \in X$ with $x \neq y$, where $a, b, c \geq 0, a+2 b+2 c s=1$ and $b s+c s^{2}<1$, then $T$ has $a$ unique fixed point $x^{*}$ in $X$. For any $x \in X$, the sequence $\left\{T^{n} x\right\}$ b-converges to $x^{*}$.

Proof. Let $x \in X$ and $x_{n}=T^{n} x$, for all $n \in \mathbb{N} \cup\{0\}$. If there exists $n_{0} \in \mathbb{N} \cup\{0\}$ such that $x_{n_{0}+1}=x_{n_{0}}$, that is, $T x_{n_{0}}=x_{n_{0}}$, then $x_{n_{0}}$ is a fixed point of $T$.

Without loss of generality, we always assume that $x_{n+1} \neq x_{n}$ for any $n \in \mathbb{N} \cup\{0\}$. Making full use of (11), we speculate

$$
\begin{aligned}
\tau+F\left(d_{n}\right) & \leq F\left(a d_{n-1}+b\left(d_{n}+d_{n-1}\right)+c d\left(x_{n-1}, x_{n+1}\right)\right) \\
& \leq F\left(a d_{n-1}+b\left(d_{n}+d_{n-1}\right)+c s\left(d_{n-1}+d_{n}\right)\right) \\
& =F\left((b+c s) d_{n}+(a+b+c s) d_{n-1}\right) .
\end{aligned}
$$

That is, $\left(F_{4}^{\lambda}\right)$ holds. Consequently, $T$ is a convex $F$-contraction. Via Lemma 1 , there exists $x^{*} \in X$ such that $x^{*}=\lim _{n \rightarrow \infty} x_{n}$.

In the following, we prove that $x^{*}$ is a fixed point of $T$. To this end, we suppose that $x^{*} \neq T x^{*}$ is absurd. Then

$$
d\left(x^{*}, T x^{*}\right) \leq s\left[d\left(x^{*}, x_{n+1}\right)+d\left(x_{n+1}, T x^{*}\right)\right]
$$

and

$$
d\left(x_{n+1}, T x^{*}\right) \leq s\left[d\left(x_{n+1}, x^{*}\right)+d\left(x^{*}, T x^{*}\right)\right]
$$

imply that

$$
\frac{1}{s} d\left(x^{*}, T x^{*}\right) \leq \liminf _{n \rightarrow \infty} d\left(x_{n+1}, T x^{*}\right) \leq \limsup _{n \rightarrow \infty} d\left(x_{n+1}, T x^{*}\right) \leq s d\left(x^{*}, T x^{*}\right) .
$$

Put $l=\liminf _{n \rightarrow \infty} d\left(x_{n+1}, T x^{*}\right)$ and $L=\limsup _{n \rightarrow \infty} d\left(x_{n+1}, T x^{*}\right)$. Using Condition (11) and $\left(F_{1}\right)$, we have

$$
\begin{aligned}
d\left(T x_{n}, T x^{*}\right)< & a d\left(x_{n}, x^{*}\right)+b\left[d\left(x_{n}, x_{n+1}\right)+d\left(x^{*}, T x^{*}\right)\right] \\
& +c\left[d\left(x_{n}, T x^{*}\right)+d\left(x^{*}, x_{n+1}\right)\right] .
\end{aligned}
$$

Hence, taking the limit as $n \rightarrow \infty$ from both sides of (13) and considering (12), we get

$$
l \leq b d\left(x^{*}, T x^{*}\right)+c L .
$$

Hence, using (12) and (14), we obtain

$$
\frac{1}{s} d\left(x^{*}, T x^{*}\right) \leq l \leq b d\left(x^{*}, T x^{*}\right)+c L \leq b d\left(x^{*}, T x^{*}\right)+c s d\left(x^{*}, T x^{*}\right),
$$

which means that $b s+c s^{2} \geq 1$. This is a contradiction. Therefore, $x^{*}=T x^{*}$.

Finally, we need to prove the uniqueness of the fixed point. To this end, assume that $T$ has another fixed point $y^{*}$. Taking advantage of (11), we arrive at

$$
\begin{aligned}
F\left(d\left(x^{*}, y^{*}\right)\right)= & F\left(d\left(T x^{*}, T y^{*}\right)\right)<\tau+F\left(d\left(T x^{*}, T y^{*}\right)\right) \\
\leq & F\left(a d\left(x^{*}, y^{*}\right)+b\left[d\left(x^{*}, T x^{*}\right)+d\left(y^{*}, T y^{*}\right)\right]\right. \\
& \left.+c\left[d\left(x^{*}, T y^{*}\right)+d\left(y^{*}, T x^{*}\right)\right]\right) \\
= & F\left((a+2 c) d\left(x^{*}, y^{*}\right)\right),
\end{aligned}
$$

which follows immediately from Condition $\left(F_{1}\right)$ that

$$
d\left(x^{*}, y^{*}\right)<(a+2 c) d\left(x^{*}, y^{*}\right) \leq d\left(x^{*}, y^{*}\right) .
$$

This is a contradiction. 
Remark 8. Theorem 5 generalizes [13] (Corollary 2.5). By virtue of convex F-contractions and Lemma 1, we can get [13] (Theorem 2.4) and [23] (Theorem 3).

We finally pose the following problems:

Problem 1. Can Condition $\left(F_{3}^{S}\right)$ be replaced with Condition $\left(F_{3}\right)$ in our all results?

Problem 2. Does Theorem 4 hold if $s \geq 1$ is arbitrary?

Author Contributions: H.H. designed the research and wrote the paper. Z.D.M. and K.Z. wrote the draft preparation and provided the methodology. S.R. co-wrote and made revisions to the paper. H.H. handled funding acquisition. All authors have read and agreed to the published version of the manuscript.

Funding: The first author acknowledges the financial support from the Natural Science Foundation of Chongqing of China (No. cstc2020jcyj-msxmX0762), and the Initial Funding of Scientific Research for High-level Talents of Chongqing Three Gorges University of China (No. 2104/09926601).

Institutional Review Board Statement: Not applicable.

Informed Consent Statement: Not applicable.

Data Availability Statement: Not applicable.

Acknowledgments: The authors thank the editor and the referees for their valuable comments and suggestions which improved greatly the quality of this paper.

Conflicts of Interest: The authors declare no conflict of interest.

\section{References}

1. Wardowski, D. Fixed points of a new type of contractive mappings in complete metric spaces. Fixed Point Theory Appl. 2012, 2012, 94. [CrossRef]

2. Abbas, M.; Nazir, T.; Aleksić, T.L.; Radenović, S. Common fixed points of set-valued F-contraction mappings on domain of sets endowed with directed graph. Comput. Appl. Math. 2017, 36, 1607-1622. [CrossRef]

3. Altun, I.; Mınak, G.; Dag, H. Multivalued F-contractions on complete metric spaces. J. Nonlinear Convex Anal. 2015, 16, $659-666$. [CrossRef]

4. Altun, I.; Minak, G.; Olgun, M. Fixed points of multivalued nonlinear F-contractions on complete metric spaces. Nonlinear Anal. Model. Control. 2016, 21, 201-210. [CrossRef]

5. Chen, L.; Huang, S.; Li, C.; Zhao, Y. Several fixed point theorems for $F$-Contractions in complete Branciari $b$-metric spaces and applications. J. Funct. Spaces 2020, 2020, 7963242.

6. Hussain, A.; Al-Sulami, H.; Hussain, N.; Farooq, H. Newly fixed disc results using advanced contractions on F-metric space. J. Appl. Anal. Comput. 2020, 10, 2313-2322.

7. Hussain, N.; Latif, A.; Iqbal, I.; Kutbi, M.A. Fixed point results for multivalued F-contractions with application to integral and matrix equations. J. Nonlinear Convex Anal. 2019, 20, 2297-2311.

8. Kadelburg, Z; Radenović, S. Notes on some recent papers concerning F-contractions in b-metric spaces. Constr. Math. Anal. 2018, 1, 108-112. [CrossRef]

9. Mohanta, S.K.; Patra, S. Coincidence points for graph preserving generalized almost $F$-G-contractions in $b$-metric spaces. Nonlinear Stud. 2020, 27, 897-914.

10. Shoaib, M.; Sarwar, M.; Kumam, P. Multi-valued fixed point theorem via F-contraction of Nadler type and application to functional and integral equations. Bol. Soc. Parana Math. 2021, 39, 83-95. [CrossRef]

11. Taheri, A.; Farajzadeh, A.P. A new generalization of $\alpha$-type almost- $F$-contractions and $\alpha$-type $F$-Suzuki contractions in metric spaces and their fixed point theorems. Carpathian Math. Publ. 2019, 11, 475-492. [CrossRef]

12. Tomar, A.; Sharma, R. Almost $\alpha$-Hardy-Rogers-F-contractions and their applications. Armen. J. Math. 2019, 11, 1-9.

13. Wardowski, D.; Dung, N.V. Fixed points of F-weak contractions on complete metric spaces. Demonstr. Math. 2014, 47, 146-155. [CrossRef]

14. Bakhtin, I.A. The contraction principle in quasimetric spaces. Funct. Anal. 30, 1989, $26-37$.

15. Czerwik, S. Contraction mappings in b-metric spaces. Acta Math. Inform. Univ. Ostrav. 1993, 1, 5-11.

16. Kirk, W.A.; Shahzad, N. Fixed Point Theory in Distance Spaces; Springer: Berlin/Heidelberg, Germany, 2014.

17. Cosentino, V.; Vetro, P. Fixed point result for F-contractive mappings of Hardy-Rogers-Type. Filomat 2014, 28, 715-722. [CrossRef]

18. Popescu, O.; Stan, G. Two fixed point theorems concerning F-contraction in complete metric spaces. Symmetry 2020, $12,58$. [CrossRef]

19. Kannan, R. Some results on fixed points. Bull. Calcutta Math. Soc. 1968, 60, 71-76.

20. Reich, S. Some remarks concerning contraction mappings. Can. Math. Bull. 1971, 14, 121-124. [CrossRef] 
21. Tomonari, S. Fixed point theorems for single- and set-valued F-contractions in $b$-metric spaces. J. Fixed Point Theory Appl. 2018, $20,35$.

22. Chatterjea, S.K. Fixed-point theorems. Dokl. Bolg. Akad. Nauk. 1972, 25, 727-730. [CrossRef]

23. Dung, N.V.; Hang, V.T.L. A fixed point theorem for generalized F-contractions on complete metric spaces. Vietnam. J. Math. 2015, 43, 743-753. [CrossRef] 